\title{
(C) OPEN ACCESS \\ Experiential learning to increase palliative care competence among the Indigenous workforce: an Australian experience
}

\section{Shaouli Shahid, ${ }^{1,2}$ Stuart Ekberg, ${ }^{\oplus 3}$ Michele Holloway, ${ }^{1}$ Catherine Jacka, ${ }^{4}$ Patsy Yates, ${ }^{4}$ Gail Garvey, ${ }^{5}$ Sandra C Thompson ${ }^{1}$}

${ }^{1}$ WA Centre for Rural Health, University of Western Australia, Geraldton and Perth, WA, Australia

${ }^{2}$ Centre for Aboriginal Studies, Curtin University, Perth, WA, Australia

${ }^{3}$ School of Psychology \& Counselling and Institute of Health \& Biomedical Innovation Queensland University of Technology, Brisbane, Australia ${ }^{4}$ School of Nursing and Institute of Health \& Biomedical Innovation, Queensland University of Technology, Brisbane, Australia

${ }^{5}$ Wellbeing and Preventable Chronic Disease Division, Menzies School of Health Research, Charles Darwin University, Brisbane, Australia

\section{Correspondence to}

Dr Shaouli Shahid, Centre for Aboriginal Studies, Curtin University, Perth WA 6845, Australia;

s.shahid@curtin.edu.au

Received 15 December 2016 Revised 1 November 2017 Accepted 28 December 2017 Published Online First 20 January 2018

\section{Check for updates}

To cite: Shahid S, Ekberg $\mathrm{S}$, Holloway M, et al. BMJ Supportive \& Palliative Care 2019:9:158-163.

\begin{abstract}
Objectives Improving Indigenous people's access to palliative care requires a health workforce with appropriate knowledge and skills to respond to end-of-life (EOL) issues. The Indigenous component of the Program of Experience in the Palliative Approach (PEPA) includes opportunities for Indigenous health practitioners to develop skills in the palliative approach by undertaking a supervised clinical placement of up to 5 days within specialist palliative care services. This paper presents the evaluative findings of the components of an experiential learning programme and considers the broader implications for delivery of successful palliative care education programme for Indigenous people.
\end{abstract}

Methods Semistructured interviews were conducted with PEPA staff and Indigenous PEPA participants. Interviews were recorded, transcribed and key themes identified.

Results Participants reported that placements increased their confidence about engaging in conversations about EOL care and facilitated relationships and ongoing work collaboration with palliative care services. Management support was critical and placements undertaken in settings which had more experience caring for Indigenous people were preferred. Better engagement occurred where the programme included Indigenous staffing and leadership and where preplacement and postplacement preparation and mentoring were provided. Opportunities for programme improvement included building on existing postplacement and follow-up activities. Conclusions A culturally respectful experiential learning education programme has the potential to upskill Indigenous health practitioners in EOL care.

\section{INTRODUCTION}

Palliative care delivery models emphasise the importance of generalist healthcare providers (HCPs) providing the majority of end-of-life (EOL) care. $^{1}{ }^{2}$ However, gaps in education, training and support for these providers remain a barrier to realising this objective. ${ }^{2-4}$ High-quality EOL care is particularly important for Indigenous people due to the high burden of chronic and life-limiting illnesses. ${ }^{56}$ Perhaps more than other mainstream healthcare services, palliative care's holistic philosophy aligns with understandings of health within many Indigenous cultures. ${ }^{7}$ However, evidence suggests that Indigenous Australians often have poor understanding of palliative care ${ }^{8}$ difficulty accessing culturally appropriate services with appropriately trained personnel ${ }^{5910}$ and fear of services due to negative experiences or institutionalised racism, ${ }^{59}$ which can contribute to their late referral to palliative care. ${ }^{9}$ Although Indigenous Health Workers (IHWs) are well placed to meet these challenges, an insufficient number work in palliative care settings. Training programmes delivered in geographic proximity to Indigenous communities should increase participation of Indigenous HCPs in EOL care. ${ }^{11}$

Since 2007, the Program of Experience in the Palliative Approach (PEPA), managed by a National Indigenous Coordinator (NIC) and supported by a national Indigenous Reference Group (IRG), has specifically targeted education opportunities for IHWs. PEPA is administered at state and territory levels (hereafter referred to as 'jurisdictions'), so the delivery of the programme varies according to local administrative requirements and organisational capacities, with some jurisdictions employing Indigenous Project Officers (IPOs) 
to work alongside the existing local PEPA team members and the NIC.

The programme offers workshops and clinical placements (including self-directed preactivities and postactivities), supported with learning guides. PEPA adopted experiential learning where teaching uses demonstration and practice opportunities. ${ }^{12}$ The educational process also included strategies promoting the transfer of learning to a learner's own environment to ensure real improvements in practice. ${ }^{1314}$ By July 2014, when the study reported here was completed, 296 IHWs had completed a placement $8.8 \%$ of the overall number of participants) and 1156 IHWs had participated in workshops (4.7\% of the overall participants). ${ }^{15}$

This paper reports on evaluation data relating to PEPA clinical placements for IHWs. The evaluation explored the experiences of PEPA's Indigenous clinical placement programme and examined how the programme conformed to the principles of Lave and Wenger's Situated Learning Theory, ${ }^{16}$ a learning process which is progressively explained throughout the article.

\section{METHODS}

\section{Sample}

Potential participants (past and current jurisdictional PEPA Managers, IPOs, IRG members) were approached by the PEPA National Office staff, based at QUT. Participants who had attended PEPA workshops and/or placements were recruited with the assistance of jurisdictional PEPA staff.

\section{Data collection}

Consenting participants were contacted by experienced qualitative researchers (SCT, SS and $\mathrm{MH}$ ) initially by telephone then a follow-up email. Two separate semistructured interview guides were used to explore the experiences of programme participants and programme managers by telephone interviews. Interviews ranging from 15 to $80 \mathrm{~min}$ in length were audiotaped and transcribed verbatim.

\section{Data analysis}

This evaluation aimed to identify the elements of the programme that facilitated optimal learning experiences for IHWs. Using the core principles of situated learning theory, thematic analysis ${ }^{17} 18$ was undertaken to identify recurrent experiences of participants. 'Situated learning theory' recognises that knowledge is acquired through deploying subject-matter (content) within the learners' ongoing experiences (community of practice and active participation) and by creating opportunities for learners to experience the real-world challenges. ${ }^{13}$ The theory ${ }^{13} 14$ emphasises the importance of social experiences, cultural appropriateness and 'two way' learning. ${ }^{19} \mathrm{MH}, \mathrm{SCT}$ and SS conducted the interviews. MH, SCT and SS were immersed in the data, kept notes of emerging themes while reading the transcripts individually and then discussed these together. Further discussion was undertaken with other authors to clarify and refine identified themes.

\section{RESULTS}

\section{Participants}

Twenty of the 35 current and former PEPA staff and 26 participants agreed to participate in the study (table 1). Eight PEPA staff and 18 participants were of Indigenous background. Of the Indigenous participants, 15 had completed placements; three attended workshops and two completed both.

Critical analysis of participants' learning experiences, challenges for learning, solutions to challenges and suggestions for improving the programme are presented below.

\section{Content and engagement in authentic activities}

Situated learning theory emphasises the importance of engagement in authentic learning experiences. Participants noted that PEPA placements promote interactive learning and create avenues for Indigenous people and services to learn about palliative care, while the palliative care providers learn about Indigenous philosophy and ways of caring. Participants took part in varied activities (attending meetings, accompanying palliative care workers on home visits, visiting the oncology and radiology units and observing patient care) that were identified as helpful in enhancing their capacity to respond to a range of real life situations. Participants referred to the activities as 'excellent', 'different

\begin{tabular}{|c|c|c|c|}
\hline PEPA Manager/IPOs & Total & Workshop/Placement participants & Total \\
\hline Indigenous Program Coordinator (past and present) & 2 & Primary Health Centre Managers (non-Indigenous) & 2 \\
\hline PEPA Managers (past and present) & 10 & Managers other (Indigenous Health) & 2 \\
\hline PEPA Project Officer & 1 & IHWs & 16 \\
\hline IPOs & 4 & Non-Indigenous Nurse & 1 \\
\hline Indigenous Consultants & 2 & Palliative Care Provider (non-Indigenous) & 5 \\
\hline Facilitator & 1 & & \\
\hline Total interviewees & 20 & Total & 26 \\
\hline
\end{tabular}


from anything that I've ever done in the past', 'real eye-opener'. Placement experiences empowered the participants:

I think it gives people confidence and permission to realise that it's normal... palliative care is an accepted ways of treating someone in the right situation, obviously and for them to come in here and look at it being done gives them a lot of confidence and validation about maybe what they were already doing (IHW, Programme participant)

An important learning outcome was the development of effective culturally appropriate communication strategies with Indigenous people about sensitive issues:

I think when we did the training ... that everybody who works in the field, whether they're allied health or whatever their position was... around effective communication and talking to someone about really heavy duty issues, private issues. (IHW, Programme participant)

Opportunities to visit patients in their own homes were preferred by some participants, as this most closely resembled the type of care they would provide within their own service:

With our palliative care patients here in this area [participant referring to their own practice environment], they felt probably a little bit more comfortable with us if we actually did a home visit and let them know that we can come out and speak to them rather than get them out of bed while they're sick and bring them into the service... so if a home visit service [during the placement] would be available then it would be fantastic. (IHW, Programme participant)

Providing placements in specialist palliative care services readily facilitated authentic learning activities, where participants could connect their experiences to their own professional practice. The participants consistently mentioned how PEPA differed from previous educational experiences in this respect.

\section{An authentic and unique practical context}

A situated learning environment creates learning opportunities that reflect the way knowledge will be used in practice. ${ }^{14}$ PEPA provided opportunities for participants to have relevant and meaningful learning experience in a clinical palliative care setting. PEPA staff tried to optimise the comfort of participants. Last minute changes in the number of patients or staff absences in the host site sometimes impacted on the appropriate delivery of the training programme and created some dissatisfaction among participants. Overall participants were appreciative of the efforts:

It was good to be in the different area, because I've been in the [name of place] area for all these years. It was good to actually meet palliative care clients that I hadn't actually spoken to in the past. (IHW, Programme participant)

IHWs were keen to interact with Indigenous patients. This enabled IHWs to link theoretical knowledge of palliative care with the reality of caring for Indigenous people. However, only a small number of services had experience in delivering palliative care to Indigenous patients, so these were used regularly for placements. Although these experiences were reported as excellent, staff from these services often felt overburdened by frequent requests to them to host placements.

A shortage of IHWs and the reluctance of some service managers to grant IHWs study leave affected IHWs' participation in PEPA. Although PEPA provided remuneration to backfill those positions, this was regarded by some as inadequate. An alternative to this standard type of placement could involve a palliative care specialist travelling to mentor a group of participants in their own workplace. Known as 'reverse PEPA placements', these addressed many obstacles for IHWs participating in PEPA. However, these same challenges were often faced by palliative care specialists who were required to travel to deliver reverse PEPA placements, which limited the scope for offering this type of placement.

Where feasible, reverse PEPA placements were considered by some as providing more appropriate support in an Indigenous context, enabling the facilitator to gain an in-depth understanding of the work environment and of the challenges faced by IHWs. This process allowed the facilitators to tailor learning opportunities to best meet the IHWs' needs:

So it was really interesting to talk with them and to hear what they had to say. Sometimes we were inside, sometimes we were outside, we'd mix it up, we did short blocks of learning with a long coffee break and with a long lunch break. So it wasn't really rigid but at the same time we got through everything. (Reverse PEPA palliative care provider)

However, some PEPA staff reported that this method of placements was very labour intensive. Recruiting specialist palliative care staff to act as facilitators and have them onsite for a period of time was challenging due to their existing clinical commitments. Despite those challenges, participants highlighted the importance of creating learning contexts that reflect the way they will use their actual professional practice.

\section{Community of practice}

Situated learning theory acknowledges the importance of both cultural (in this context, an Indigenous community of practice) and professional knowledge (in this context, specialist palliative care). ${ }^{20}$ This approach, adopted within Indigenous PEPA, recognises both types of knowledge. Both palliative care specialists and learners were engaged in designing learning opportunities, which enhanced the cultural acceptability of the 
programme. Indigenous PEPA allowed participants to observe the experienced practitioners at work, while at the same time providing participants with access to an Indigenous mentor or elder at some placement sites. In some settings, an Indigenous doctor or nurse provided opportunities for reflection on expert cultural and clinical considerations. Allocated Indigenous mentors had an important role in the success of placements:

I met one of the consultants and from Day One I spent about an hour or so talking to her about things, my feelings and my experience and how I felt about working in this specific area. It was very helpful... (IHW, Programme participant)

Participants reported that both mentors should ideally be experienced in working with Indigenous people and should share information and provide support, with cultural guidance sought from local elders and health staff. Although the programme was not fully facilitated by Indigenous staff in all jurisdictions, it was conducted in a culturally appropriate manner. Participants reported feeling comfortable to ask questions and that staff were competent in addressing those queries.

Efforts to engage Indigenous healthcare facilities and communities differed across jurisdictions. The lack of a dedicated IPO in some jurisdictions was reported as impeding Indigenous community engagement. Varying levels of health literacy in Indigenous communities and differences in understanding and knowledge around death and dying also made engagement challenging. Training for Indigenous participants required: (1) resources for meaningful engagement with Indigenous communities (eg, time dedicated to community engagement); (2) cultural safety of participants (eg, provision of an Indigenous mentor); (3) culturally appropriate resources and (4) consideration of and assistance with the complexities of travel for participants across Australia.

\section{Assessment of transfer of learning, active participation and postplacement support}

Situated learning theory emphasises on the importance of facilitating transfer of learning into practice. To consolidate learning following PEPA placements, participants were asked to implement some postplacement activities in their workplaces to support palliative care practices. Maintaining contact with PEPA participants postplacement was identified as important to support application of learning. In some jurisdictions, PEPA staff provided regular feedback through their quarterly newsletters. Some participants were linked to their local palliative care team where they met regularly to discuss local patients and their needs. Postplacement activities were effective where PEPA staff were well connected with the other local palliative care services:
When I came back after I did the PEPA placement I then had the opportunity to work with some of the palliative care staff with a few of our clients in the area. (IHW, Programme participant)

Some services offered additional learning opportunities (not necessarily PEPA initiatives), for example, workshops, seminars. Others encouraged participants to complete a postplacement workplace activity sheet. In one jurisdiction, participants were offered free attendance at another workshop of jurisdictional palliative care providers to help broaden relevant networks. All interviewees said they received additional resources, such as booklets, pamphlets and contact details of palliative and other supportive services, from PEPA on completion of their placement.

The level of support for placement participants varied, depending on workloads and on their line manager's awareness and perception of the importance of a palliative approach. IHWs benefited from regular contact with a mentor known to them and who they trusted. Support was enhanced where two or more staff from a service (in some instances managers as well) attended the placement together, showing the benefits of targeting a range of health professionals simultaneously rather than a specific group in isolation. Both participants and services benefitted from this 'team approach' (group or pair), which supported participants to implement their learning into practice. This approach was also useful to address fear, anxiety and stress regarding long-distance travel of many participants who were from remote locations and who would rarely travel. One participant described the support arrangements after completing a placement undertaken with the manager and two other IHWs:

... [the manager] is the advisor. If we get a palliative patient so after the passing and everything we come together as a group and handover with every staff that's had connection with that person and looked after them till the end and we support each other. Yeah, like see how we feel, are we doing things that we should have done better, or if and how they're feeling. (IHW, Programme participant)

To assess the effectiveness of the learning process and its impact on practice, evaluation needs to be seamlessly integrated with postlearning activities. PEPA managers sent preplacement evaluation questionnaires 1 week prior to the placement and postevaluation questionnaires at 3 months postplacement. Some participants felt that these standardised fixed response components of the evaluation form could not capture stories and in-depth descriptions of experiences raising whether innovative follow-up strategies could consolidate participant learning and assist the transfer of learning into practice. 


\section{DISCUSSION AND CONCLUSION}

Limited access to palliative care for Indigenous populations is a global problem. ${ }^{23}$ Gaps in service delivery $^{22} 23$ and understandings of palliative care among Indigenous people is recognised as contributing to this problem. ${ }^{8} 2124$ Evidence around Indigenousspecific initiatives that address these gaps are limited. This paper addresses these problems by evaluating an experiential learning approach designed to increase the capacity for IHWs to deliver palliative care.

The Indigenous PEPA programme was developed in consultation with Indigenous people, has been overseen by Indigenous people and is underpinned by a cultural respect framework. PEPA acknowledges that knowledge and learning environments are closely associated with a learner's sociocultural orientation ${ }^{25}$ and provides a practical, problem-based approach within a community of practice that is designed to support meaning and appropriate learning. This evaluation highlights the challenges and prospects for PEPA to provide learning opportunities that reflect the principles of situated learning theory. Particular strengths include: authentic learning opportunities, delivered in practical contexts, with a culturally appropriate community of practice, and an emphasis on transferring learning. There were, however, also a range of challenges. The strengths identified highlight the importance of addressing these challenges to create culturally appropriate opportunities to learn about palliative care.

The design of PEPA reflects Indigenous learning styles by allowing two-way experiential learning that occurs in a relevant, practice-based setting. ${ }^{26}$ Although there was diversity in programme delivery and participants' experiences, some factors that enhanced programme achievements for IHWs included: the availability of a dedicated IPO, culturally appropriate and flexible programme delivery, effective participant preparation prior to placement, debriefing, line-managers' support and sustaining networks and outcomes postplacement. The presence and involvement of Indigenous mentors optimised participant comfort and learning. Reverse PEPA placements, in which a palliative care specialist spends time in the service where IHWs are employed, were challenging to organise but particularly valued as effective learning experiences. No other programme comparable with PEPA was identified in the literature. Several Palliative Care Toolkits developed for Indigenous people in $\mathrm{Canada}^{27}$ and for Indigenous Australians ${ }^{28}$ are available, but evidence of how well they have been used to promote education and training in palliative care is lacking.

Sustainable community engagement is crucial for experiential learning programmes to enhance capacity of a particular community. ${ }^{29} 30$ Acknowledging the sensitive nature of the topic and creating a supportive inclusive environment to discuss holistic, person and family-centred EOL care is important. Given
Indigenous communities are diverse, programmes such as PEPA need to be and can be tailored to the needs of underserved and local communities. ${ }^{31}$

Study findings relied on a small sample of participants due to difficulties locating those who completed Indigenous PEPA since many had left their listed place of employment and there was no central registration or tracking of those completing PEPA placements. Interviews occurred well after the placement was completed. Efforts to assess the long-term impact of the programme require participants to recall their experiences. Despite these limitations, this study provides an overview of how an Indigenous-focused, EOL experiential learning education programme was delivered and highlights the strength and learning from this programme as a way of skilling Indigenous people in EOL care.

Contributors SS prepared the first draft of the manuscript. SS, SCT and MH conducted the interviews and analysed the data. SCT mentored the whole process, analysed data and contributed to writing. SE, CJ and PY provided support during data collection. All authors made considerable contributions to writing the manuscript and approved the final draft.

Funding The Program of Experience in the Palliative Approach is funded by the Australian Government Department of Health, who also funded the study reported here. This study was undertaken under the auspices of the Centre of Research Excellence in Discovering Indigenous Strategies to improve Cancer Outcomes Via Engagement, Research Translation and Training (DISCOVER-TT CRE, funded by the National Health and Medical Research Council (\#1041111) and the Strategic Research Partnership to improve cancer control for Indigenous Australians (STREP Ca-CIndA, funded through Cancer Council NSW (SRP 13-01) with supplementary funding from Cancer Council WA). We also acknowledge the ongoing support of the Lowitja Institute, Australia's National Institute for Aboriginal and Torres Strait Islander Health Research. Dr Shaouli Shahid and Professor Gail Garvey are supported by an NHMRC Early Career Fellowships (APP1037386 and APP1105399, respectively).

Disclaimer The views expressed in this publication are those of the authors and do not necessarily reflect the views of the funding agencies.

Competing interests SS, MH, GG and SCT report no competing interest. SE, CJ and PY have all been involved in the development, implementation and management of PEPA.

Ethics approval Queensland University of Technology (QUT) Human Research Ethics Committee (Approval reference: 1200000183).

Provenance and peer review Not commissioned; externally peer reviewed.

Data sharing statement If required, we can share additional unpublished data from the study via email.

Open access This is an open access article distributed in accordance with the Creative Commons Attribution Non Commercial (CC BY-NC 4.0) license, which permits others to distribute, remix, adapt, build upon this work noncommercially, and license their derivative works on different terms, provided the original work is properly cited and the use is non-commercial. See: http://creativecommons.org/licenses/ by-nc/4.0/

(C) Article author(s) (or their employer(s) unless otherwise stated in the text of the article) 2019. All rights reserved. 
No commercial use is permitted unless otherwise expressly granted.

\section{REFERENCES}

1 Australian Capital Territory Government. Palliative care services plan 2013-2017. Canberra: ACT Government, 2012. https://www.health.act.gov.au/sites/default/files/Policy_and Plan/Palliative\%20Care\%20Services\%20Plan\%202013-2017. pdf (accessed 01 Nov 2017).

2 Canadian Hospice Palliative Care Association. The way forward national framework: a roadmap for an integrated palliative approach to care. Ottawa, Ontario: Government of Canada, 2015. http://hpcintegration.ca/media/55100/HD\% 20CHPCA\%20The\%20Way\%20Forward\%20-020Topline $\%$ 20Results\%20-\%20BC.pdf (accessed 01 Nov 2017).

3 Giovanni LA. End-of-life care in United States: current reality and future promise-a policy review. Nurs Econ 2012;30:125-6.

4 Palliative Care Australia. A Guide to Palliative Care Service Development: a Population based approach. Deakin West: Palliative Care Australia, 2005. http://palliativecare.org.au/ wp-content/uploads/2015/05/A-guide-to-palliative-care-servicedevelopment-a-population-based-approach.pdf. (accessed 01 Nov 2017).

5 Prince H, Kelley M. An Integrative Framework for conducting palliative care research with First Nations communities. J Palliat Care 2010;26:47-53.

6 Australian Institute of Health and Welfare. The health and welfare of Australia's Aboriginal and Torres Strait Islander people, an overview 2011. Canberra: AIHW, 2011. Contract No: Cat. no. IHW 42.

7 Lock M. Aboriginal Holistic Health: a critical review, 2007. Discussion Paper Series No 2. https://www.lowitja.org.au/sites/ default/files/docs/DP2_Mark-Lock.pdf

8 Shahid S, Bessarab D, Van Schaik KD, et al. Improving palliative care outcomes for Aboriginal Australians: service providers' perspectives. BMC Palliat Care 2013;12:26.

9 O'Brien AP, Bloomer MJ, McGrath P, et al. Considering Aboriginal palliative care models: the challenges for mainstream services. Rural Remote Health 2013;13.

10 McGrath P, Holewa H. End-of-life care of Aboriginal peoples in remote locations: language issues. Aust J Prim Health 2007;13:18-27.

11 National Aboriginal Health Organization. Discussion paper on end of life/ Palliative care for Aboriginal people. Canada: National Aboriginal Health Organization, 2002.

12 Kolb D. Experiential Learning: Experience as the source of learning and development. Englewood Cliffs, NJ: Prentice Hall, 1984.

13 Lave J, Wenger E. Situated learning: legitimate peripheral participation. Cambridge, UK: Cambridge University Press, 1991.

14 Stein D. Situated Learning in Adult Education, 1998. ERIC Digest No 195. http://files.eric.ed.gov/fulltext/ED418250.pdf.
15 Holloway M, Shahid S, Thompson SC. Evaluation of the Aboriginal and Torres Strait component of the Program of Experience in the Palliative Approach (PEPA). Perth, WA: WA Centre for Rural Health, University of Western Australia, 2014.

16 Lave J, Wenger E. Situated Learning. New York: Cambridge, 1991.

17 Creswell JW. Research design: qualitative, quantitative and mixed methods approaches. 2nd Edn. California: Sage publications, Inc, 2003.

18 Snape D, Spencer L. Ritchie JL, The Foundations of Qualitative Research. London, Thousand Oaks, New Delhi: SAGE Publications, 2003.

19 Wilson BG, Myers KM. Situated cognition in theoretical and practical context. In: Jonassen D, Jonassen DH, Land S, eds. Theoretical Foundations of Learning Environments: Taylor \& Francis, 2000.

20 Jacobson W. Learning, culture and learning culture. ‘dult Educ Q 1996;47:15-28.

21 Decourtney CA, Branch PK, Morgan KM. Gathering information to develop palliative care programs for Alaska's Aboriginal peoples. J Palliat Care 2010;26:22-31.

22 Sullivan K, Johnston L, Colyer C, et al. National Indigenous Palliative Care Needs Study. Canberra: Commonwealth Department of Health and Ageing, 2003.

23 To T, Boughey M. Referral patterns to a palliative care service in rural Australia servicing indigenous Australians. Intern Med J 2010;40:772-6.

24 McGrath P. Aboriginal cultural practices on caring for the deceased person: findings and recommendations. Int J Palliat Nurs 2007;13:418-25.

25 Herrington J, Oliver R. An instructional design framework for authentic learning environments. University of Wollongong Research Online. 2000. http://ro.uow.edu.au/cgi/viewcontent. cgi? article $=1031 \&$ context $=$ edupapers

26 Byrnes J. Aboriginal learning styles and adult education: is a synthesis possible? Australian Journal of Adult and Community Education 1993;33:157-71.

27 Aboriginal Cancer Control Unit. Tools for the journey: palliative care in first nations, inuit and métis communities, a resource toolkit. Ontario: Cancer Care Ontario, 2014.

28 McGrath P, Watson J, Derschow B, et al. Indigenous palliative care service delivery- a living model: National Health \& Medical Research Council (NHMRC), 2004.

29 O'Connor K. Experiential learning in an Indigenous context: Integration of place, experience and criticality in educational practice: Canadian Council on Learning, 2010.

30 Ryan MM, Marchioro G, 2008. A model for experiential learning and community engagement in marketing research. Teaching \& Learning Conference. The University of Notre Dame Australia ResearchOnline

31 Frerichs L, Schumacher K, Watanabe-Galloway S, et al. Development of the Northern Plains Native Family Cancer Caregiver Education Program. J Palliat Care 2012;28:52-9. 